\title{
A COMPARISON BETWEEN THE EXPERIMENTAL AND THEORETICAL IMPACT PRESSURES ACTING ON A HORIZONTAL QUASI-RIGID CYLINDER DURING VERTICAL WATER ENTRY
}

\author{
D. Van Nuffel ${ }^{1 *}$, K.S. Vepa ${ }^{1}$, I. De Baere ${ }^{1}$, Pascal Lava ${ }^{2}$, M. Kersemans ${ }^{1}$, J. Degrieck ${ }^{1}$, J. De \\ Rouck $^{3}$, W. Van Paepegem ${ }^{1}$ \\ ${ }^{1}$ Mechanics of Materials and Structures, Department of Materials Science and Engineering, Ghent \\ University, Technologiepark-Zwijnaarde 903, 9052 Zwijnaarde, Belgium \\ ${ }^{2}$ Mechanics, Materials and Processes, Catholic University College Sint-Lieven, Gebroeders \\ Desmetstraat 1, 9000 Gent, Belgium \\ ${ }^{3}$ Department of Coastal Engineering, Ghent University, Technologiepark-Zwijnaarde 904, 9052 \\ Zwijnaarde, Belgium \\ *Corresponding author: e-mail: Diederik.VanNuffel@UGent.be; phone: +32 93310435
}

\begin{abstract}
This paper presents a detailed study on the local pressures acting on the surface of a quasi-rigid cylinder during vertical water entry into a flat water surface. This water entry event is an approximation of bottom wave slamming of cylindrical structures, which is a typical problem for many naval constructions. Hence, the results from this research can be used during the design of cylindrical structures in a slamming sensitive environment. The paper shows the impact pressure results of a large set of slamming drop experiments with a cylindrical model, on a rigorously instrumented test set-up using state-of-the-art equipment. The obtained experimental data is compared in detail with the governing theoretical formulations concerning cylinder slamming. For deadrise angles larger than $4.25^{\circ}$, a good agreement is found with an averaged version of the Wagner theory. This indicates that the Wagner theory is a good estimate for impact pressures acting on a horizontal rigid cylinder during vertical water entry, for deadrise angles larger than $4.25^{\circ}$.
\end{abstract}

\section{Keywords}

Water impact, cylinder slamming, vertical water entry

$\begin{array}{ll}\text { Abbreviations } & \\ \text { PVC } & \text { polyvinylchloride } \\ \text { ICP } & \text { integrated circuit piezoelectric } \\ \text { MOSFET } & \text { metal-oxide-semiconductor field-effect transistor } \\ \text { DTC } & \text { discharge time constant } \\ \text { DIC } & \text { digital image correlation }\end{array}$

\section{Introduction}

Water slamming is known as one of the most important loads which naval constructions have to deal with. It can occur due to a breaking wave hitting a structure (breaking wave slamming), or by a structure plunging with its bottom into the water after (bottom slamming). The water impact can be so violent that it causes severe damage to the structure. This ability of damaging the structure originates from the high energetic density impact which occurs during a very short period, i.e. a few milliseconds after the first contact between the water and the object surface. It causes very high local pressures which move very fast over the object's surface.

For vessels and other moving bodies, slamming is avoided as much as possible by heading to calmer seas or by imposing a speed reduction in harsh sea conditions (Faltinsen, 1990). However, for offshore constructions with a fixed oceanographic location (e.g. drilling platforms), previous options are not possible.

These fixed constructions are often composed of cylindrical structural members. Floating or fixed platforms and jackets can be taken as an example, since they are built up of many horizontal and vertical cylindrical trusses. The main problem for these constructions is the repeated water entry and exit of the cylindrical construction elements located in the splash zone of the waves. Especially in heave sea conditions, the velocity at which these 
cylindrical elements enter the water can be so fast, that large bottom slamming loads occur. This type of situation also often occurs at the cylindrical bulbous bows of large ships in heavy sea conditions and may also introduce possible hazards during pipelaying at moments of large waves. These examples of cylindrical bottom slamming events are illustrated in Figure 1.

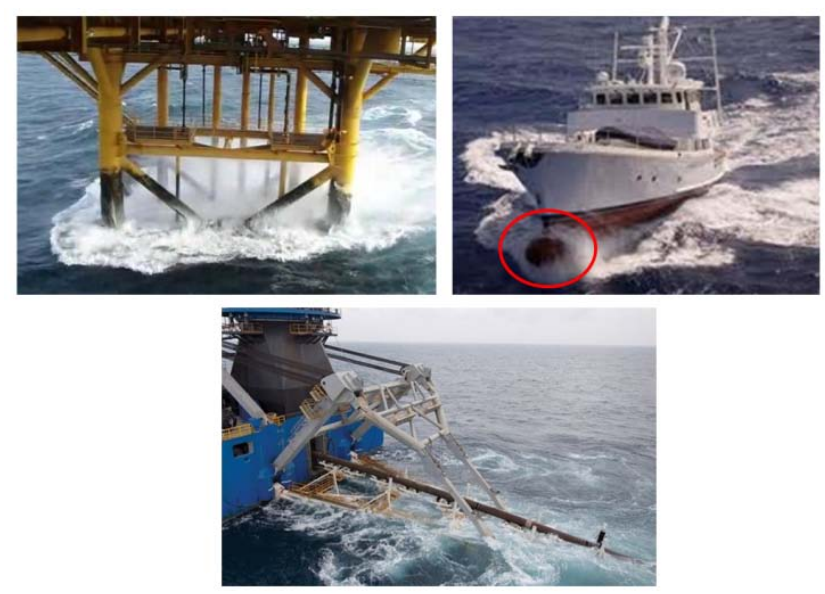

Figure 1: Examples of cylindrical bottom slamming

Cylindrical bottom slamming is thus a common problem in many applications. It is important to have precise information on the level of slamming in a specific situation to judge if it poses a possible hazard to the complete construction. Mostly, the degree of slamming is characterized by the magnitude of the impact pressures which occur at the object's surface during water entry.

Widely accepted theoretical formulations on these local pressures occurring during cylindrical slamming were derived by von Kármán (von Kármán, 1929) and Wagner (Wagner, 1932). However, little experimental information has been gathered in the meantime in order to validate these theoretical models. Greenhow and Lin (Greenhow and Lin, 1983) performed drop experiments on a cylindrical object, but only focused on the flow around the object during water entry. Campbell and Weynberg (Campbell and Weynberg, 1980), Lin and Shieh (Lin and Shieh, 1997) and Colicchio et al. (Colicchio et al., 2009) performed pressure measurements during similar experiments, but it has been shown in (Van Nuffel et al., 2012) that these publications used a data sampling rate which is too small to obtain reliable data for estimating the maximum values of the pressure pulses. Hence, new experiments using recent, state-of-the-art equipment turn out to be necessary.

This paper shows the results of an extensive experimental campaign on cylindrical bottom slamming using an rigorously instrumented test set-up. Similarly to the experiments performed in (Campbell and Weynberg, 1980; Colicchio et al., 2009; Lin and Shieh, 1997), bottom slamming is obtained by dropping a horizontal cylindrical model on a flat water surface. A detailed comparison between the measured and the theoretical values obtained from (von Kármán, 1929; Wagner, 1932) will be performed to investigate the validity of these theories as design guidelines.

\section{Materials and methods}

\subsection{Experimental test set-up}

A vertical drop test rig as presented in Figure 2 was designed to perform the vertical drop experiments. It contains a T-shaped impactor which slides along two vertical rails towards a water basin at the bottom. This water tank measures $1 \mathrm{~m}$ by $1.2 \mathrm{~m}$ and has a water depth of $0.6 \mathrm{~m}$. The test object is fixed at the bottom of the impactor. A window is provided at the front side wall of the tank to enable video recordings of the slamming phenomenon. 


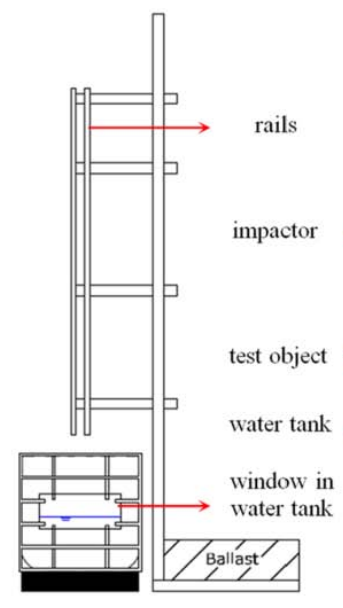

(a)

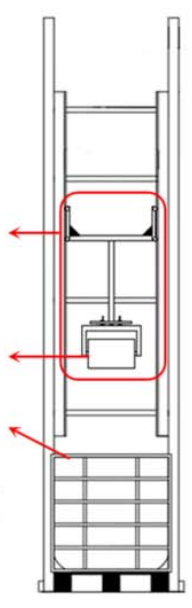

(b)

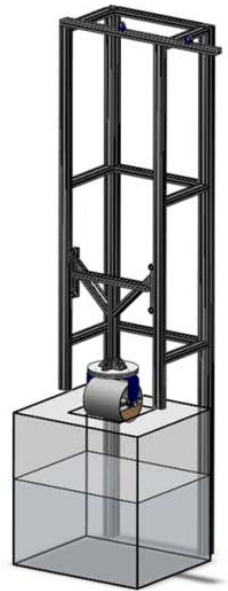

(c)

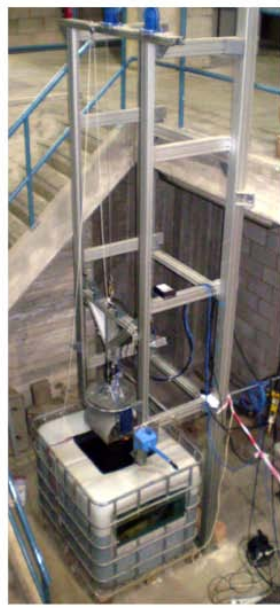

(d)

Figure 2: The experimental test set-up: (a) schematic side view; (b) schematic front view; (c) CAD drawing, (d) photograph

\subsection{Cylindrical test object}

The quasi-rigid cylindrical test object is designed as a tube made of polyvinylchloride (PVC) (see Figure 3). Steel frameworks are inserted inside this tube to guarantee the rigidity of the object. Figure 3 illustrates the geometry of these inserts. The dimensions of the cylinder are chosen according to the dimensions of the experimental set-up and the availability of the material, i.e. a length of $350 \mathrm{~mm}$, an external diameter of $315 \mathrm{~mm}$ and a wall thickness of $6.2 \mathrm{~mm}$. The vertical sides of the cylinder are partly covered with a plastic membrane to avoid water flowing into the tube during water penetration.
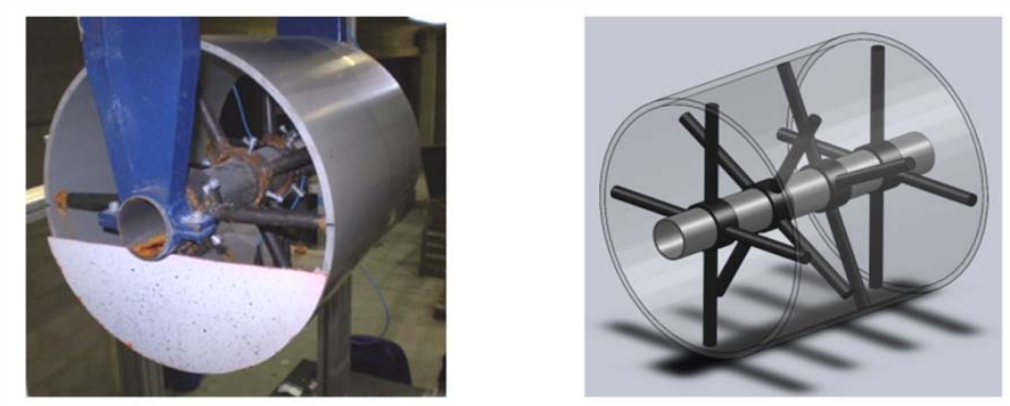

Figure 3: The quasi rigid cylindrical test object and its steel reinforcements

\subsection{Instrumentation}

Figure 4 shows an overview of the most important instrumentation which has been used during the experiments. The following sections describe the details of this experimental equipment. 


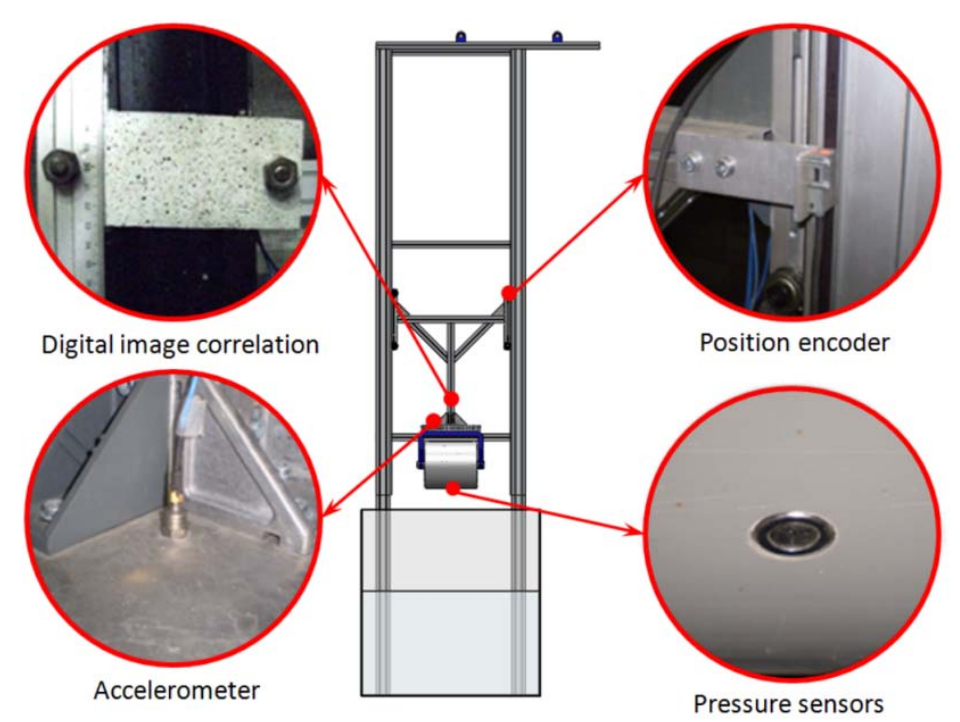

Figure 4: Overview of the instrumentation of the experimental test set-up

\subsubsection{Pressure sensors}

Pressure sensors mounted into the cylinder wall are used to measure the local loads acting on the cylindrical structure during water penetration. The pressure sensors used are dynamic integrated circuit piezoelectric sensors (ICP sensors) from PCB Piezotronics (see Figure 5). They incorporate piezoelectric quartz crystals which generate an electrostatic charge when being loaded. This charge output is proportional to the input pressure and is converted into a low impedance voltage signal by a built-in MOSFET microelectronic amplifier. A low impedance signal is required to prevent triboelectric cable noise in the output signal (PCB Piezotronics, 2013a). For the experiments performed in this paper, the sensors of type 102A06 and 102B06 are used. They have the same dimensions, the same performance and have both a range up to 34.5 bar (PCB Piezotronics, 2013b). The diameter of both sensor diaphragms is $\mathrm{d}_{\text {sens }}=5 \mathrm{~mm}$.

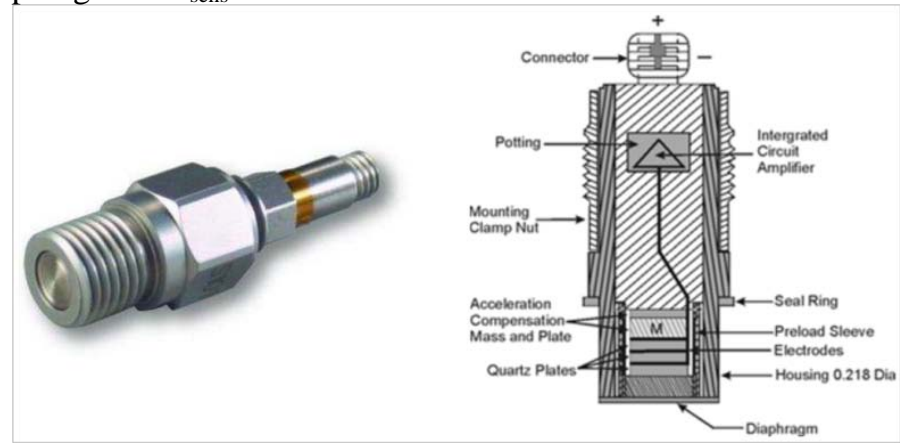

Figure 5: Dynamic piezoelectric pressure sensor of PCB Piezotronics and its internal configuration (PCB Piezotronics, 2013b)

The use of piezoelectric crystals as sensing elements makes these types of sensors very well suited for recording highly dynamic pressures, since these materials typically exhibit very high natural frequencies and have an excellent linear behaviour over a wide amplitude range (PCB Piezotronics, 2013a). The sensors used for this paper have a resonance frequency larger than $500 \mathrm{kHz}$ (PCB Piezotronics, 2013b). However, the drawback of this technique is that this type of sensor is not able to measure static pressures. Although the crystal is very well electrically insulated, it exhibits charge leakage causing the output signal dropping to zero after some time, even if there is a constant pressure applied on the sensor diaphragm. This leakage rate is characterized by the discharge time constant (DTC) which is defined as the time necessary to discharge the output till $37 \%$ of the input value after a step input (PCB Piezotronics, 2013a).

The two sensors are placed in parallel on the same meridian of the cylinder in order to have 2 simultaneous measurements. The sensor 102A06 is placed exactly in the middle of the cylinder's length, while sensor $102 \mathrm{~B} 06$ is placed $8 \mathrm{~cm}$ from the side. Pressure measurements at different positions on the circumference of the cylinder 
are possible by rotating the whole cylindrical tube including the mounted pressure sensors around its central axis over the desired angle, as shown in Figure 6.
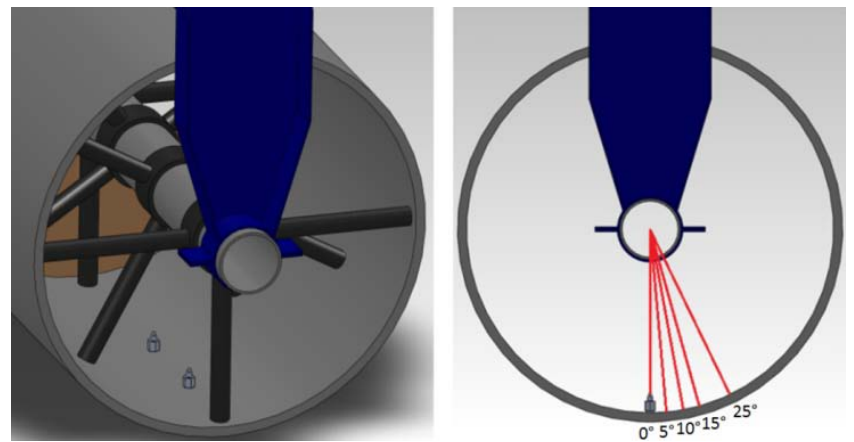

Figure 6: CAD drawing showing the position of the pressure sensors and the tested angles

Measuring local pressures is a sensitive process, and several factors may influence the pressure recordings. Some measures should therefore be taken to enable correct and reproducible experimental results. A detailed study on how to record dynamic impact pressures during water entry is given by Van Nuffel (Van Nuffel et al., 2012). This study resulted in a list of 5 recommendations in order to enable good pressure measurements:

- Use a data sampling rate of at least $300 \mathrm{kHz}$ for impact speeds up to $5 \mathrm{~m} / \mathrm{s}$

- Ensure flush mounting of the sensors with respect to the cylindrical wall

- Avoid temperature shock

- Dry the object surface before each test

- Wait for the water surface to be completely calm before each test.

These recommendations were taken into account during the experiments performed in this paper. A data sampling rate of $5 \mathrm{MHz}$ was used to record the pressures in this paper, which is large enough when compared to the minimum required one.

\subsubsection{Position encoder}

The position encoder serves as one of the instruments for measuring the impact velocity. The conversion of position to velocity is performed by differentiating the measured signal in time. The impact velocity is then obtained as the velocity of the cylinder at the moment of the first contact with the water. It is used to assess the amount of initial kinetic energy of the object just before impact. By using this initial kinetic energy rather than the initial potential energy calculated from the drop height, it is possible to present the impact pressure results independently from the friction losses occurring between the impactor wheels and the vertical rails which are specific for each test set-up. By presenting the pressure results as function of impact velocity, they can be compared with these from other experimental set-ups.

The position sensor used is of type LIMES LI20/B1 from Kübler and it is positioned on the T-shaped top structure of the impactor (Kübler, 2013). It is an inductive sensor which slides over a magnetic strip provided on the overall length of the drop set-up. This strip contains a set of alternate north and south poles. Each time the sensor passes one of these poles, it records pulses which are then converted to a position value. The sensor and the magnetic strip are depicted in Figure 7. Since the time rate of change of the position signal is much smaller than for the pressure signals, a data sampling frequency of $100 \mathrm{kHz}$ is large enough to acquire all the information from this signal.
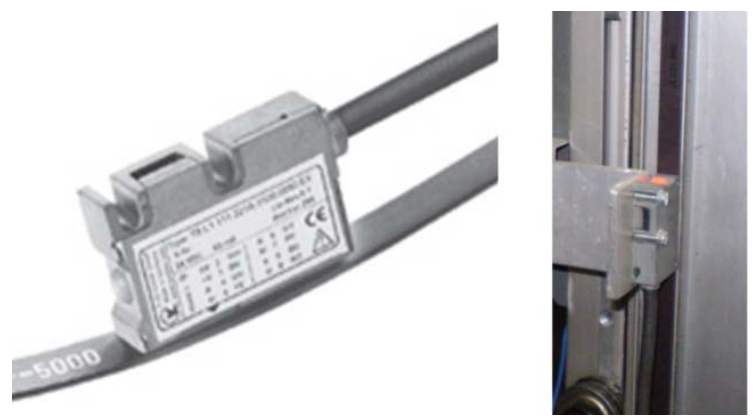

Figure 7: The inductive position encoder (Kübler, 2013) 


\subsubsection{Accelerometer}

Another sensor which has been used for measuring the impact velocity is an accelerometer. Integration in time is now required to convert the acceleration signal into a velocity signal. An accelerometer of type 8704B500 from Kistler with a range of $500 \mathrm{~g}$ and a resonance frequency of $54 \mathrm{kHz}$ is mounted above the cylinder (Kistler, 2013). This sensor is built up of two piezoelectric quartz shear-sensing elements. At the side of these elements, small masses are provided which cause shearing of the quartz crystals when the system is accelerated or decelerated. This shearing introduces electrostatic charges which are then again converted into low impedance voltage signals. An image of the acceleration sensor and its internal construction is shown in Figure 8. The data sampling frequency used for this sensor type is the same as for the position encoder (100 kHz).

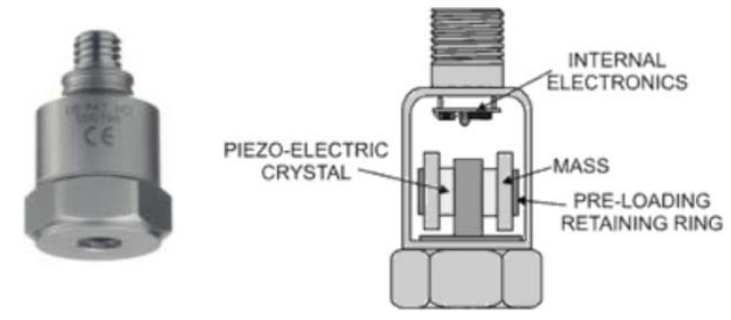

Figure 8: The accelerometer and its internal construction (Kistler, 2013)

\subsubsection{High speed camera}

A high speed camera is used during the experiments for two purposes. First of all, high speed images are taken from the cylinder during water impact to have a better understanding of the flow around the cylinder. Furthermore, it has also been used to measure the position and the velocity of the cylinder versus time. This has been done by using the Digital Image Correlation (DIC) technique (Palanivelu et al., 2009). This is a noninterferometric optical technique which is widely accepted as a powerful tool for measuring surface displacements and surface deformations. To calculate the displacement of a feature in the images, the signature of each pixel of that feature is tracked throughout the list of images. The signature of a pixel is a unique value which characterizes that pixel, e.g. the grey value. It can also be calculated using properties of the neighbouring pixels, e.g. the grey value of the neighbouring pixels. To improve the contrast between the pixels of the images, a black on white speckle pattern has been applied on the T-shaped top structure of the impactor and the camera is focused on this pattern. A camera of type APX-RS of Photron has been used during the experiments with a frame rate of 7500 fps (Photron, 2013). A schematic overview of the measurement set-up is shown in Figure 9. The software used to analyze the images and convert them to a position signal is MatchID (Lava, 2012).

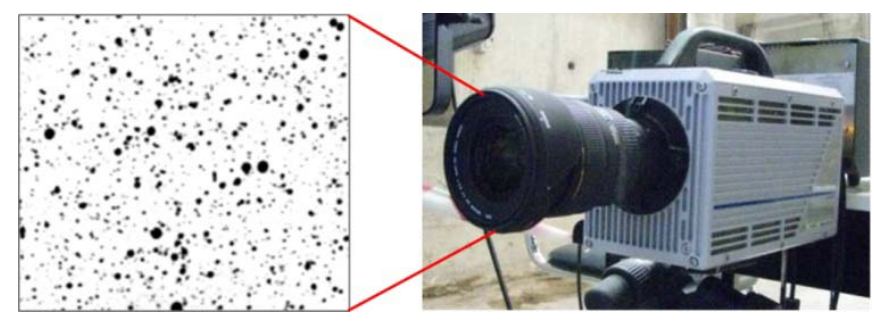

Figure 9: Measurement set-up of the DIC technique

\subsubsection{Data acquisition}

To acquire and process the measured data, the Genesis Gen5i portable data acquisition system is used (HBM, 2013). It is an all-in-one multichannel oscilloscope, data acquisition system and industrial computer which can be considered as the state of the art in its domain. The system can obtain data at a frequency up to $100 \mathrm{MHz}$, and all channels are electrically insulated from each other to prevent interference from one channel to another.

The data acquisition of all the measuring equipment starts at the moment that the cylindrical test model touches the water surface, i.e. when the position signal crosses the zero level. At that moment, the Gen5i acquisition system generates a trigger signal which triggers the acquisition system and which also triggers the recording of the high speed camera. In this way, the recordings taken at different sampling rates and the high speed images are synchronized and can be correlated with each other. 


\section{Experimental results and discussion}

This section describes the experimental results of the test campaign. This will proceed in two stages: first, the measurements of the impact velocity will be discussed in detail since they give a notion on the initial energy level of each test. This is followed by a thorough investigation of the measured impact pressures which are linked to the impact velocities to characterize the cylinder slamming magnitude for given levels of the initial kinetic energy.

\subsection{Impact velocity}

Figure 10 shows the velocity time history recorded during a slamming drop test with the cylindrical test object for a drop height of $1 \mathrm{~m}$. Figure 10 (a) shows as an example the overall velocity time history of the complete recording obtained from the position encoder, while Figure 10 (b) shows a detailed view of the velocity at the moment of the impact obtained from the DIC technique. From the graphs it can be observed that the velocity is zero at the start of the experiment. When the cylinder starts falling, the velocity increases linearly till a maximum value is obtained. At the moment of the first contact of the cylinder with the water, the cylinder speed is not immediately decreasing, but stays on the same value for a few milliseconds. It is only after these initial stages of the impact, when the submerged portion of the cylinder generates enough resistance, that the test object is decelerated and that the cylinder speed decreases smoothly. At a moment $t=0.13 \mathrm{~s}$, the velocity abruptly decreases to zero by the action of the motion dampers which are installed on the test set-up to prevent the test objects from hitting the bottom of the water tank.

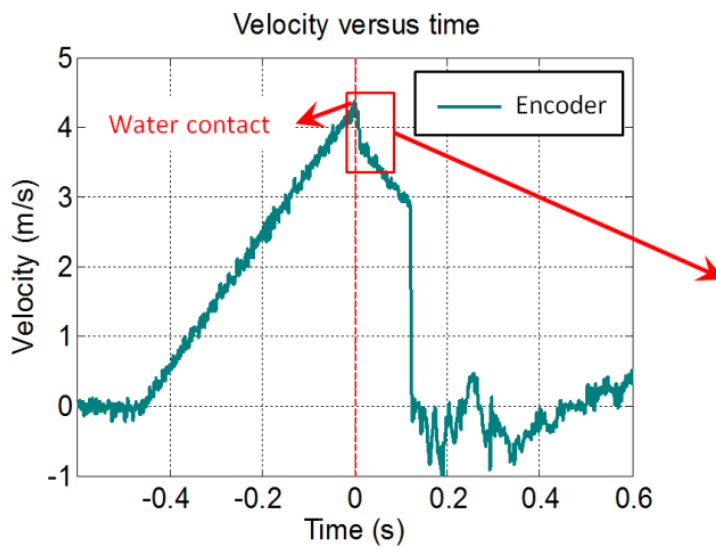

(a)

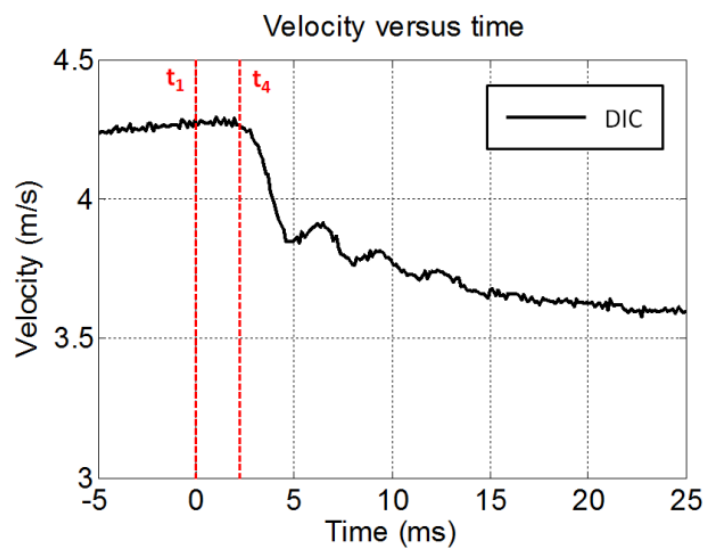

(b)

Figure 10: Time history of the velocity of the cylinder for a slamming experiment with $1 \mathrm{~m}$ drop height

The impact velocities corresponding with a certain drop height are obtained as the velocity values just at the moment of the first contact of the cylindrical test model with the water, i.e. when the acquisition system is triggered. An overview of the tested impact velocities is given in Figure 11. The presented data points represent the average of the velocity values obtained from the encoder data, the DIC data and the accelerometer data for three slamming experiments per tested drop height and per tested deadrise angle. The graph also shows the uncertainty on these impact velocity values by means of error bars. These error bars show that the scatter on the measured impact velocities is small indicating that the measurements can be assumed reproducible.

Furthermore, the graph shows that the measured impact velocities slightly differ from the theoretical expected ones calculated according to the following formula:

$$
v=\sqrt{2 g h}
$$

The difference grows with growing drop height. This clearly shows the effect of friction between the impactor wheels and the vertical rails of the experimental test set-up. 


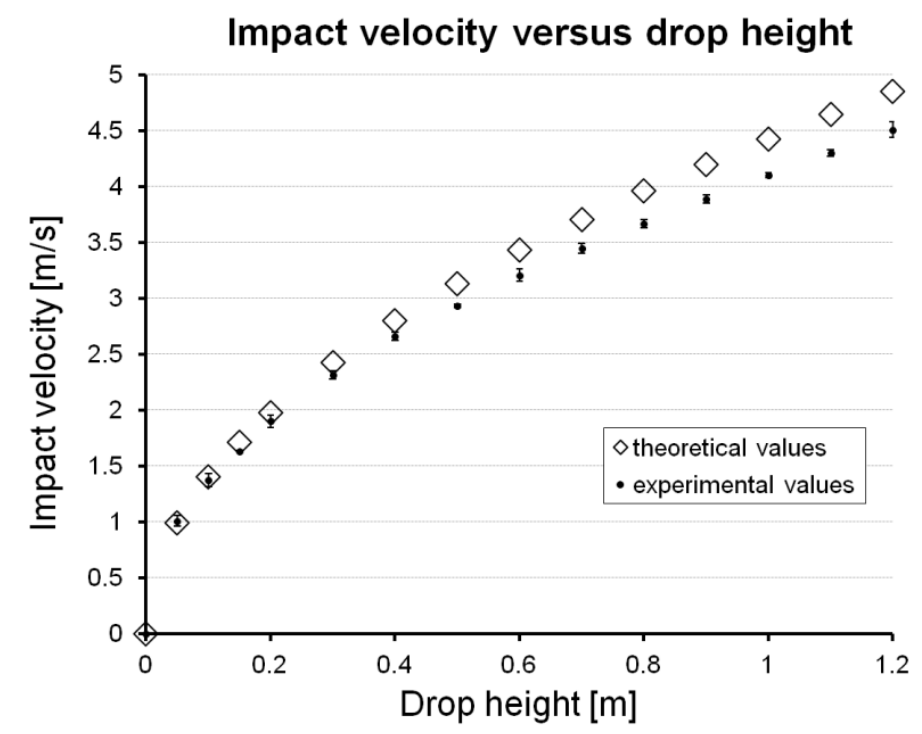

Figure 11: Comparison between the experimental and theoretical impact velocities

\subsection{Impact Pressures}

\subsubsection{Time history}

Figure 12 shows time plots for the pressures acting on the cylinder during impact on the calm water surface. All graphs are taken for an impact velocity of $4.1 \mathrm{~m} / \mathrm{s}$ which corresponds with a drop height of $1 \mathrm{~m}$. From top to bottom, the deadrise angle is increased from $0^{\circ}$ till $25^{\circ}$, and the time scale is the same for every graph. The deadrise angle is the angle between the diaphragm surface of the pressure sensor and the water surface.

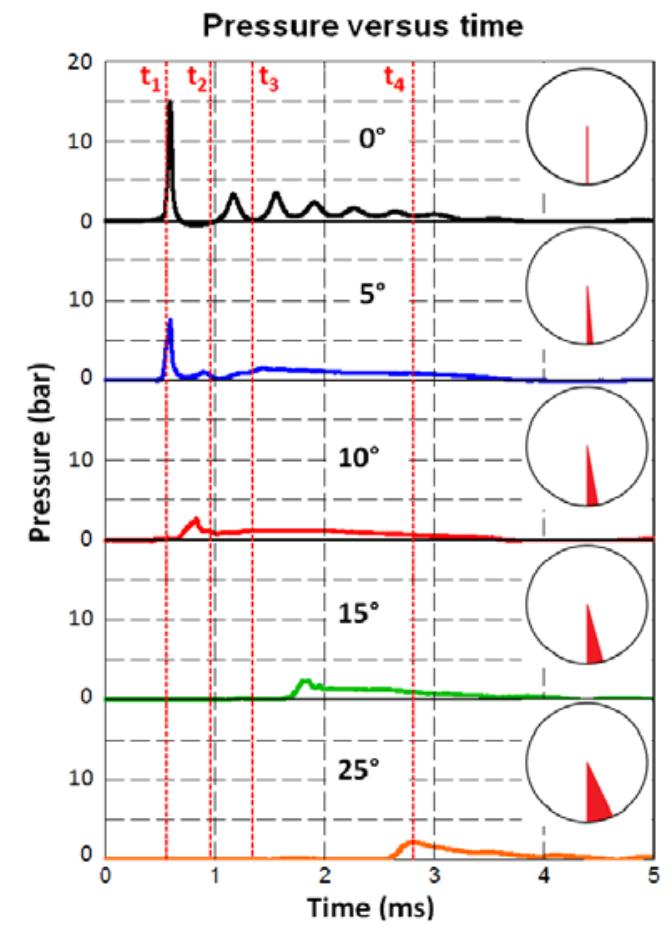

Figure 12: Time plots for the pressure measurements at 5 different deadrise angles $\left(0^{\circ}, 5^{\circ}, 10^{\circ}, 15^{\circ}\right.$ and $\left.25^{\circ}\right)$ and at an impact speed of $4.1 \mathrm{~m} / \mathrm{s}$.

From these graphs it can be observed that the impact of the cylinder on the water starts with a high pressure pulse (in the order of 15 bar) with a very short duration (in the order of $200 \mu \mathrm{s}$ ) at the bottom of the cylinder. As 
the cylinder penetrates the water, this pressure peak travels further along the surface of the cylinder while its peak value reduces and its duration increases. This reduction is mainly due to the increasing deadrise angle. A small part of the reduction may also be contributed to the slightly decreasing velocity after impact, but it is assumed that this effect is negligible since the impact velocity hardly changes during the initial stages of the impact. The pressure peak always occurs in the intersection zone of the cylindrical surface and the water surface, i.e. at the root of the water jet. In this zone, called the inner domain (Victor, 2007), the water is compressed and separates into a part which forms the water jet along the surface of the cylinder. Finally, this water jet will separate from the cylinder and no pressure pulse will be registered anymore at larger deadrise angles. The time moments $t_{1}$ and $t_{4}$ correspond with the high speed images depicted in Figure 13. It can be observed that at the time $t_{4}$, when the pressure reaches its peak in the pressure measurement at $25^{\circ}$, the physical deadrise angle exactly matches $25^{\circ}$ indicating that the pressure peak is thus reached in the spray root of the jet.
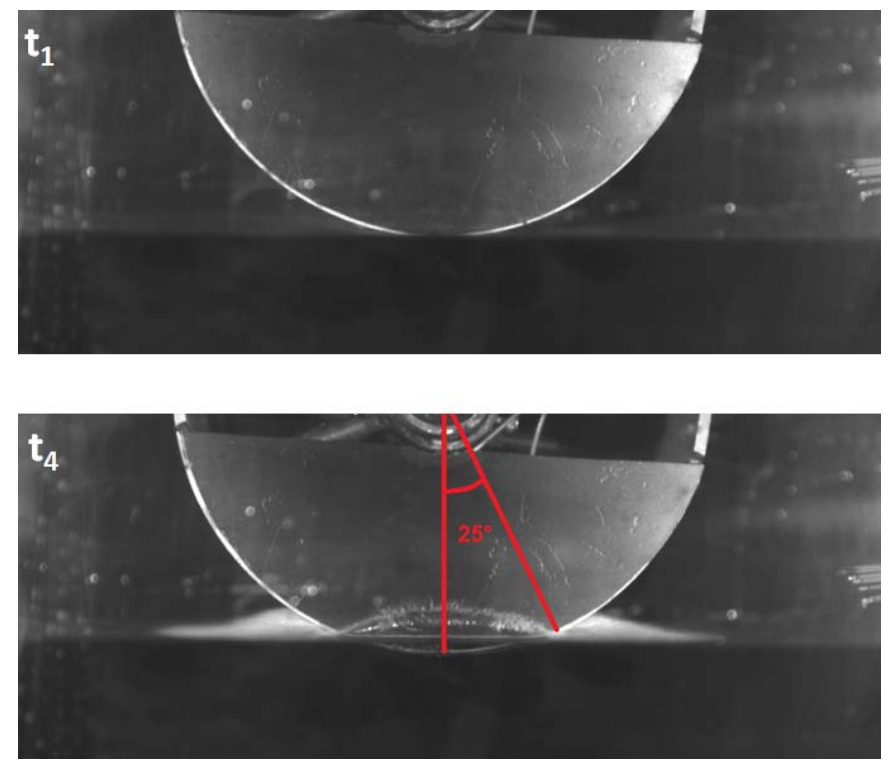

Figure 13: Camera images at two different time frames. $t_{1}$ : first contact of the cylinder with the water; $t_{4}$ : pressure peak at $25^{\circ}$

Furthermore, it can be observed from Figure 12 that for the pressure time history at deadrise angle also smaller pressure peaks are observed after the first slamming peak, which occur at a periodic time interval of about $0.35 \mathrm{~ms}$ (frequency of $2857 \mathrm{~Hz}$ ) and which dampen out in time. A similar oscillatory pressure time history for the pressure recording at the bottom of the cylinder has also been observed by Lin and shieh (Lin and Shieh, 1997). Such oscillations are not observed in the pressure time histories recorded at the other deadrise angles. A detailed investigation was carried out to find an explanation for these oscillations.

If the oscillations were caused by structural vibrations of the cylinder due to the sudden impact, then these oscillations in the impact pressure would also be expected in the recordings at the other deadrise angles. Hence, this possibility seems unlikely as an explanation.

Another hypothesis is that the secondary pressure peaks are caused by the pressure waves which are generated in the water tank at the moment of impact, which subsequently reflect at the bottom of the tank and then again reach the diaphragm of the sensors. The back and forth travelling of these pressure waves would then explain the oscillatory peaks in the pressure time histories recorded at the bottom. However, this hypothesis is also very unlikely since the generated pressure waves propagate with a cylindrical wave front in the tank and rapidly decay in magnitude. When they travel twice the distance from the point of impact till the bottom of the water tank, it is expected that the magnitude of the pressure wave has decreased so much that it has no significant effect anymore on the pressure recordings. Moreover, it has been observed that the time that the pressure wave needs to travel twice the depth $J$ of the water tank does not match the time interval between two pressure pulses. This travelling time can be calculated by dividing the travel distance by the velocity of sound $\gamma_{w}$ in the water since this is the speed the pressure wave travels with. The travelling time of the pressure wave is thus:

$$
\Delta t=\frac{2 J}{\gamma_{w}}=\frac{2 \cdot 0.6 \mathrm{~m}}{1497 \mathrm{~m} / \mathrm{s}}=0.80 \mathrm{~ms}
$$


This value is more than double the value which is observed in the pressure recordings. Hence, the previous hypothesis seems also unlikely to explain the secondary pressure peaks in the pressure recordings at the bottom of the cylindrical test object.

Lin and Shieh (Lin and Shieh, 1997) assumed that the repeatedly compression and expansion of an air pocket which is formed during the very initial stages of the impact just at the bottom of the cylindrical model caused the secondary pulses in the pressure recordings at this location. Since the air pocket is only formed very locally at the bottom of the cylinder, this might explain why the secondary pressure pulses are not recorded at the other deadrise angles. However, they could not confirm this assumption. In order to verify this possibility, camera images were taken in the current experiments from the underside of the tested cylinder, with the camera positioned as illustrated in Figure 14.

Figure 15 shows the recorded images at three time moments shortly after the first contact of the cylinder with the water. These images confirm the presence of an air pocket very locally at the bottom of the cylinder which rapidly disappears, and hence confirms the assumption made by Lin and shieh (Lin and Shieh, 1997). However, at time $t_{4}$, the air pocket is not visible anymore on the camera images, while the pressure recordings still show a small oscillating signal for a very short period after this time moment $t_{4}$. This is probably caused by the fact that the air pocket lasts longer at the location of the pressure sensors since the diaphragms of these sensors are locally flat which makes it more difficult for the entrapped air to escape at these locations.

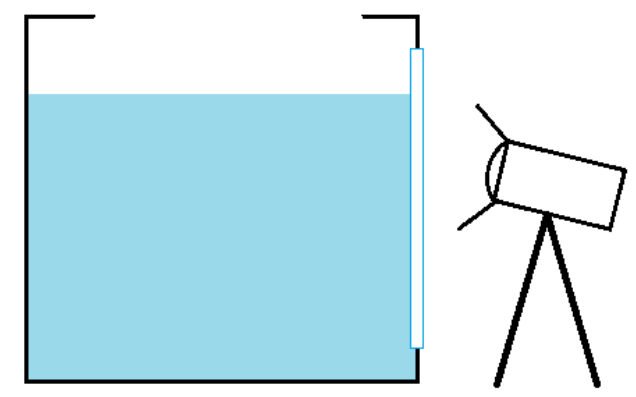

Figure 14: Schematic view of the camera position for the verification of the presence of entrapped air at the bottom of the cylinder
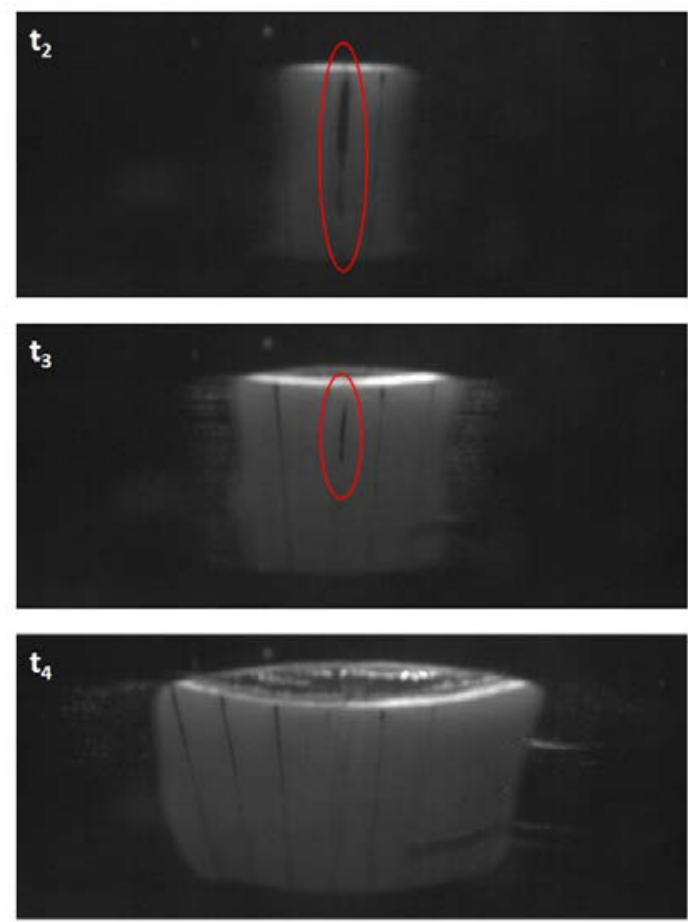

Figure 15: Camera images from the bottom of the cylinder during water impact 
Wagner (Wagner, 1932) derived a mathematical theory in 1932 for describing the time history of the impact pressures at the surface of a body during vertical water entry. This theory, which was introduced by von Kármán in 1929 as the flat plate theory (von Kármán, 1929) was based on the impact of a flat plate with varying width on a horizontal flat water surface (see Figure 16 (a) and (b)). The width as function of time determines the geometry of the object surface. The fluid was assumed irrotational and incompressible, thus viscous effects could be neglected. Furthermore, a constant entry velocity was presumed. However, due to the flat plate approach, the theory is only valid for small deadrise angles. For a cylinder penetrating the water, the following equation was derived:

$$
p_{\text {wagner }}=\frac{1}{2} \rho U^{2}\left[1-\frac{x(t)^{2}}{4 U R t-x(t)^{2}}+\frac{4}{\sqrt{\frac{4 U t}{R}-\left(\frac{x(t)^{2}}{R^{2}}\right)}}\right]
$$

With: $\quad \rho=$ water density, $1000 \mathrm{~kg} / \mathrm{m}^{3}$

$U=$ constant entry velocity

$R=$ cylinder radius

$t=$ time elapsed after the first contact of the cylinder with the water

$x(t)=$ half width of the cross section of the object with a theoretically unelevated water surface, as function of time elapsed after the first contact (see Figure 16 (b))

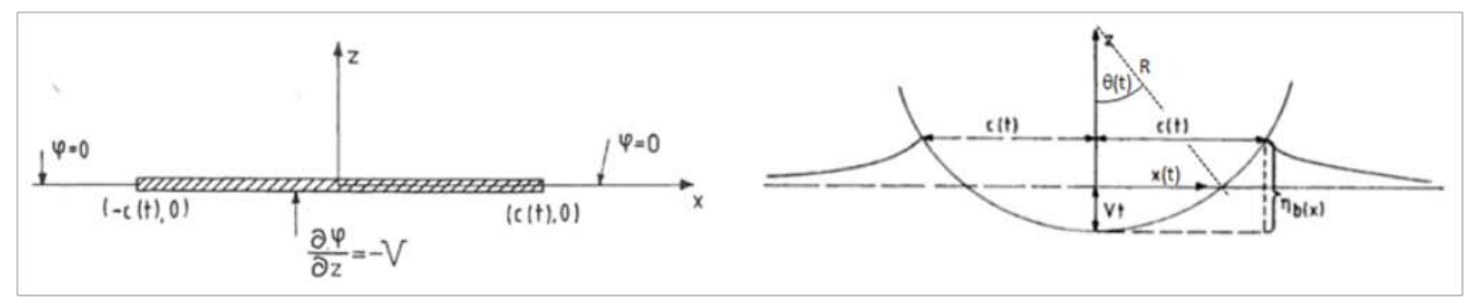

(a)

(b)

Figure 16: (a) Flat plate theory of von Kármán (von Kármán, 1929); (b) Flat plate theory for the case of a cylindrical object

(Wagner, 1932)

In cylindrical coordinates $(x(t)=R \sin (\theta(t)))$, this equation becomes:

$$
p_{\text {wagner }}=\frac{1}{2} \rho U^{2}\left[1-\frac{R^{2} \sin (\theta(t))^{2}}{4 U R t-R^{2} \sin (\theta(t))^{2}}+\frac{4}{\sqrt{\frac{4 U t}{R}-\left(\sin (\theta(t))^{2}\right)}}\right]
$$

With: $\theta(t)=$ deadrise angle as function of time elapsed after the first contact

Figure 17 shows the time history for the pressure at the cylindrical surface according to Wagner for an impact velocity of $4.1 \mathrm{~m} / \mathrm{s}$ at a deadrise angle of $5^{\circ}$. The corresponding experimental curve has been added for comparison. The shape of both curves is quite similar in the sense that the impact starts with a very high and short pressure pulse and then gradually returns to zero pressure. However, a large difference in the magnitude of the pressure pulse can be observed. A detailed investigation concerning this large difference is given in the following section 


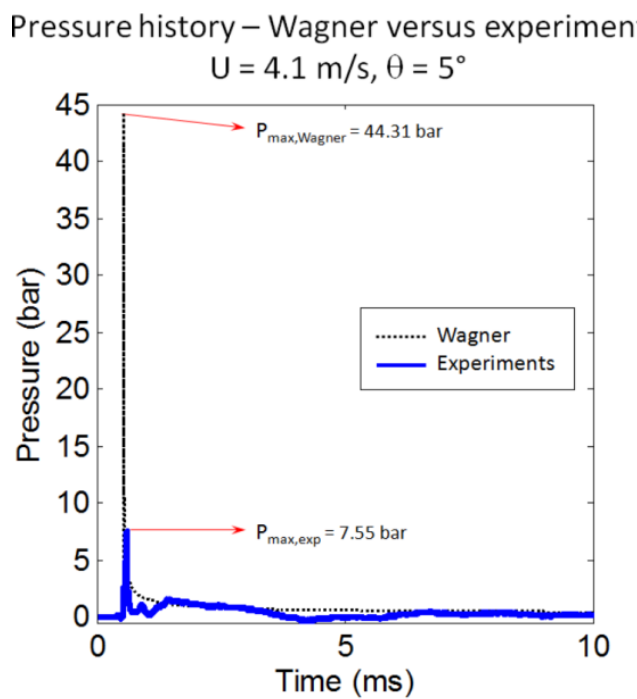

Figure 17: Pressure time history at the cylindrical surface for an impact velocity of $4.1 \mathrm{~m} / \mathrm{s}$ at a deadrise angle of $5^{\circ}$ : Wagner theory compared with experiments

\subsubsection{Peak pressures}

Three slamming drop tests are performed per tested drop height and deadrise angle. With two pressure transducers installed in the cylindrical test object, this results in six pressure recordings per test case. However, before presenting the impact pressure values as the average of these six recordings, it is important to consider the difference in the recorded slamming pressures between the two used pressure transducers, which are located at the same deadrise angle, but at another position with respect to the cylinder's length. As such, the effect of the three-dimensionality of the flow around the cylindrical test model on the impact pressures during water impact can be investigated. It is important to take into account the effect of the flow in the longitudinal direction of the cylinder on the measured impact pressures to make the results from this study also representative for cylinders with larger aspect ratios (length/diameter-ratios), since these are more often used in industrial offshore constructions.

Figure 18 shows the impact pressure values for both pressure sensors located at $0^{\circ}$ deadrise angle for all experiments as function of impact velocity. The transducer of type 102A06 is the sensor located in the middle of the cylinder's length, while the sensor 102B06 is the sensor located $8 \mathrm{~cm}$ from the side on the same meridian. It is observed that the deviations of the impact pressure values between both pressure transducers are within the scatter level of the overall pressure results, which is reasonably small. Hence, no significant indications are found for large three-dimensional flow effects. Since there is no significant difference in the pressure recordings of both pressure transducers their average value will be presented in the following paragraphs.

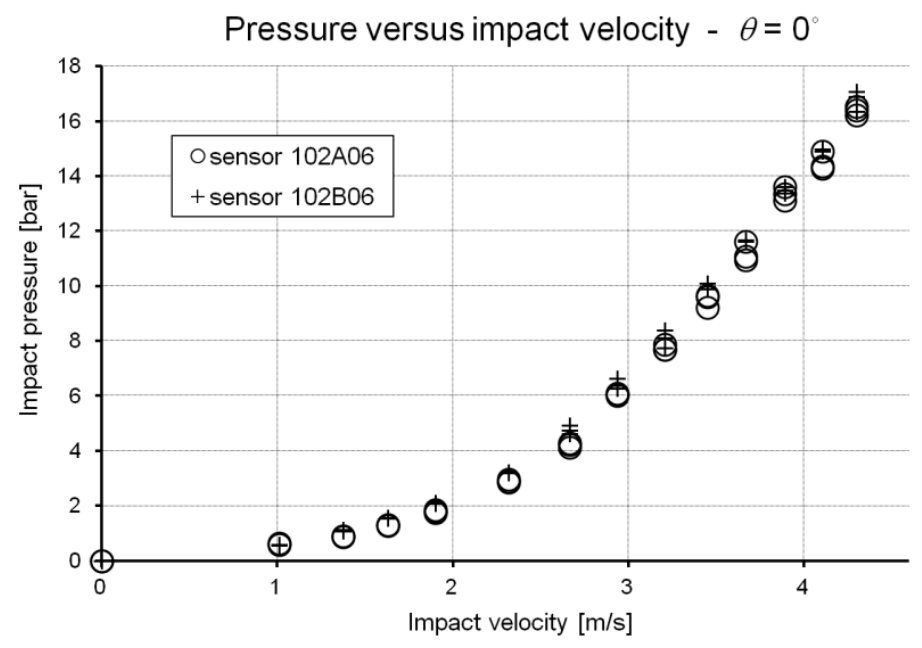

Figure 18: Impact pressure measurements for sensor 102A06 and 102B06 for all experiments with the sensors located at $0^{\circ}$ deadrise angle as function of impact velocity 
An overview of the average pressure peak values as function of impact velocity is given in Figure 19 and Appendix A for different deadrise angles. For the deadrise angles $10^{\circ}, 15^{\circ}$ and $25^{\circ}$, the measurements are very close to each other. Figure 20 gives a better view on these results. The uncertainty has been expressed in the graphs in terms of error bars, based on the standard deviation as reported in Appendix A. The standard deviation indicates a good reproducibility for the pressure measurements at $0^{\circ}$ and $5^{\circ}$ deadrise angle, but more scatter for the recordings at larger angles.

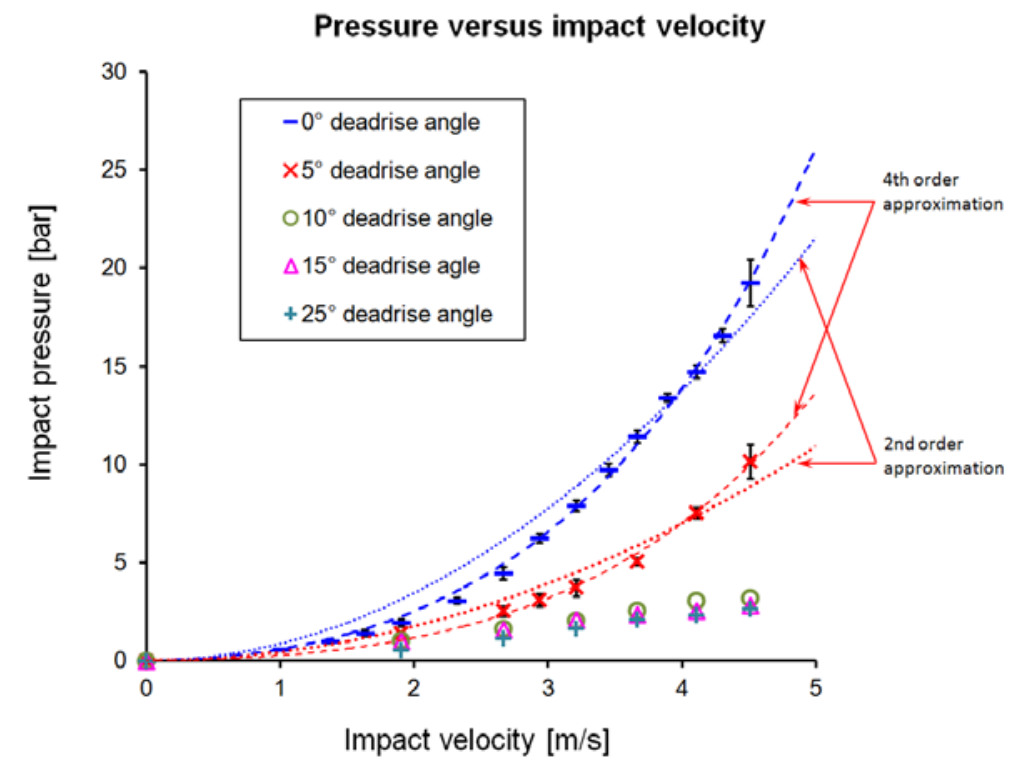

Figure 19: Overview of the measured pressure peak values as function of impact velocity for different deadrise angles

Pressure versus impact velocity

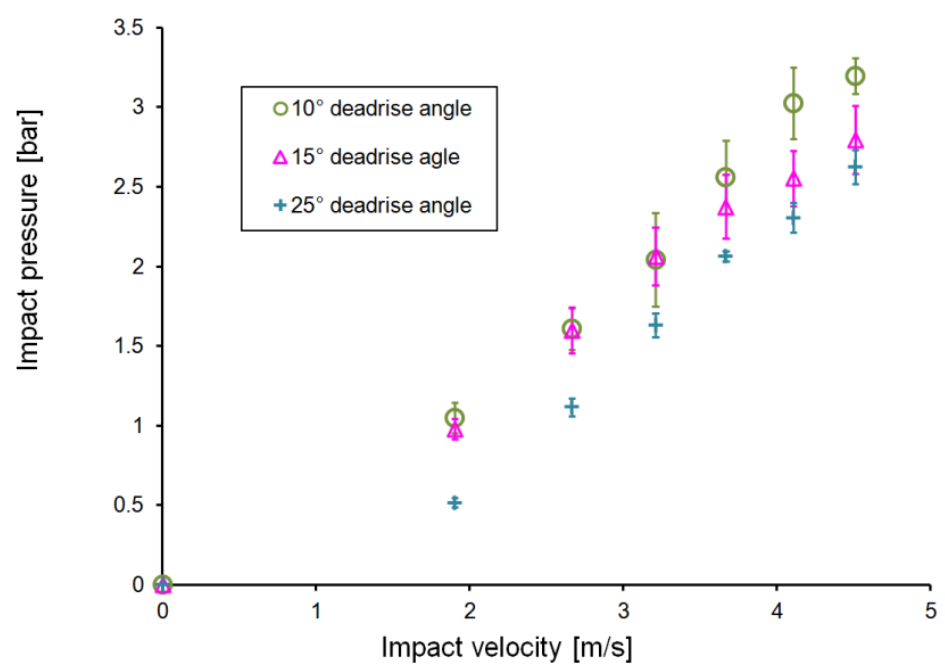

Figure 20: Overview of the measured pressure peak values as function of impact velocity for deadrise angles $10^{\circ}, 15^{\circ}$ and $25^{\circ}$

For the pressure peaks measured at $0^{\circ}$ and $5^{\circ}$ deadrise angle, a clear trend can be observed. The data points follow a $4^{\text {th }}$ order relationship rather than a second order trend, which shows that the local loads acting on the cylinder rise very fast with increasing impact velocity. For bottom slamming of cylindrical structures at large speed, extremely high local pressures will thus occur during the first impact stages. For the measurements at $10^{\circ}$, $15^{\circ}$ and $25^{\circ}$, no clear trends can be observed. Together with the larger scatter observed at these deadrise angles, this shows that water impact pressure measurements at deadrise angles larger than 10are of highly stochastic nature. 
A comparison between all the measured maximum pressures and these predicted by the Wagner theory is possible by deriving Equation (4) with respect to time and solving the obtained equation towards time. This gives the time which corresponds with the maximum of the pressure time history, as function of entry velocity and deadrise angle:

$$
t_{p, \max , \text { wagner }}=\frac{1}{16} \frac{R \sin (\theta)^{2}\left(4+\sin (\theta)^{2}\right)}{U}
$$

Substituting this time value in Equation (4) gives the pressure peak value as function of entry velocity and deadrise angle:

$$
p_{\text {max,wagner }}=\frac{1}{2} \rho U^{2}\left[1-\frac{R^{2} \sin (\theta)^{2}}{\frac{1}{4} R^{2} \sin (\theta)^{2}\left(4+\sin (\theta)^{2}\right)-R^{2} \sin (\theta)^{2}}+\frac{4}{\sqrt{\frac{1}{4} \sin (\theta)^{2}\left(4+\sin (\theta)^{2}\right)-\sin (\theta)^{2}}}\right]
$$

At the bottom of the cylinder, where the deadrise angle is $0^{\circ}$, this equation gives an infinite pressure peak. This means that, although the Wagner theory has been developed for small deadrise angles, it is not valid at the bottom of the cylinder where the deadrise angle is $0^{\circ}$. This is also the case for other small deadrise angles close to the bottom, which give unrealistic high pressure values. The reason for this can be found in Wagners assumption of water being an incompressible fluid. During the initial stages of the impact, corresponding to small deadrise angles, the water jet which moves along the cylindrical surface moves faster than the speed of sound in water. This implies a supersonic perturbation travelling over the free surface, allowing the water compressibility to play a role. These observations were also done by Feit and Skalak (Feit and Skalak, 1963), Korobkin (Korobkin, 1994) and Campana et al. (Campana et al., 2000). Compressibility should thus be taken into account during these early stages of the water penetration. However, this appeared to be difficult to implement theoretically. Von Kármán (von Kármán, 1929) determined an approximation of the maximum pressure occurring during impact of a horizontal flat plate on a calm water surface. Since the bottom zone of the cylinder can be considered flat when regarded locally, we will apply this theory for this location. The impact pressure according to von Kármán, which is called the acoustic pressure is given by:

$$
p_{\max }=\rho \gamma_{w} U
$$

With: $\gamma_{w}=$ speed of sound in water, $1497 \mathrm{~m} / \mathrm{s}$ at $25^{\circ} \mathrm{C}$.

Figure 21 shows as an example the impact pressure values as function of deadrise angle for an entry velocity of $4.1 \mathrm{~m} / \mathrm{s}$. It can be observed that below a deadrise angle of $4.25^{\circ}$, the maximum pressure as calculated by Wagner is larger than calculated by von Kármán. It can thus be assumed that below this deadrise angle value, the water compressibility starts playing a role. This indicates that for the comparison of the measured impact pressures with the theoretically predicted ones, the von Kármán theory should be used for the measurements at $0^{\circ}$, while the Wagner theory can be applied for the recordings at $5^{\circ}, 10^{\circ}, 15^{\circ}$ and $25^{\circ}$. Figure 21 also shows the experimentally obtained impact pressures for an entry velocity of $4.1 \mathrm{~m} / \mathrm{s}$ for the different tested deadrise angles. For deadrise angles smaller than $25^{\circ}$, it can be observed that the experimentally obtained values are significantly smaller than the theoretically predicted ones. 


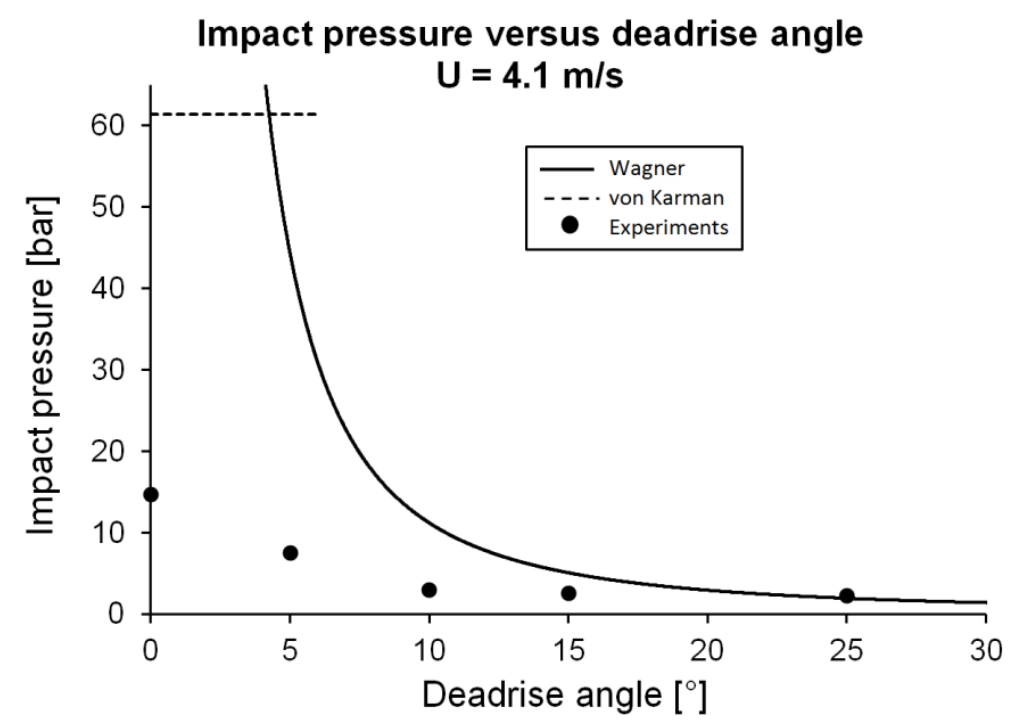

Figure 21: Impact pressure as function of deadrise angle for an entry velocity of $4.1 \mathrm{~m} / \mathrm{s}$ according to Wagner and von Kármán, and comparison with experiments

Figure 22 (a) - (e) show the comparison of the measured maximum pressures with the corresponding theoretically predicted ones as function of impact velocity.

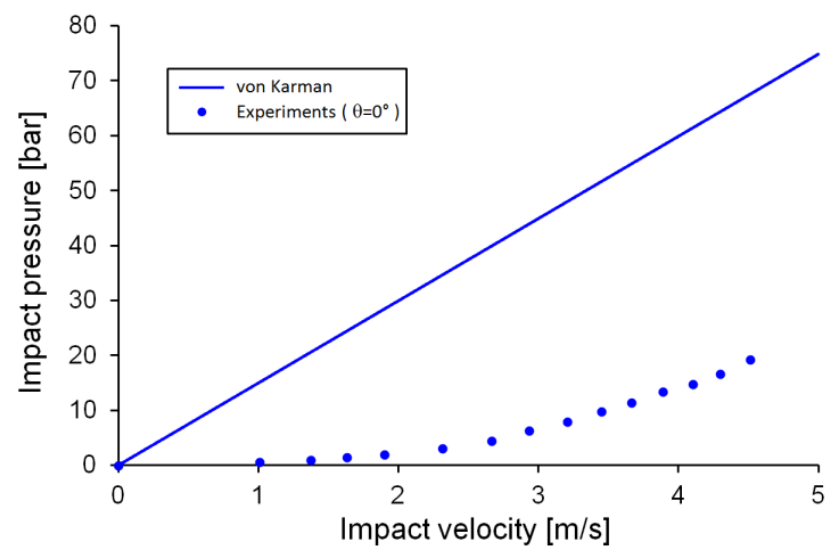

(a)

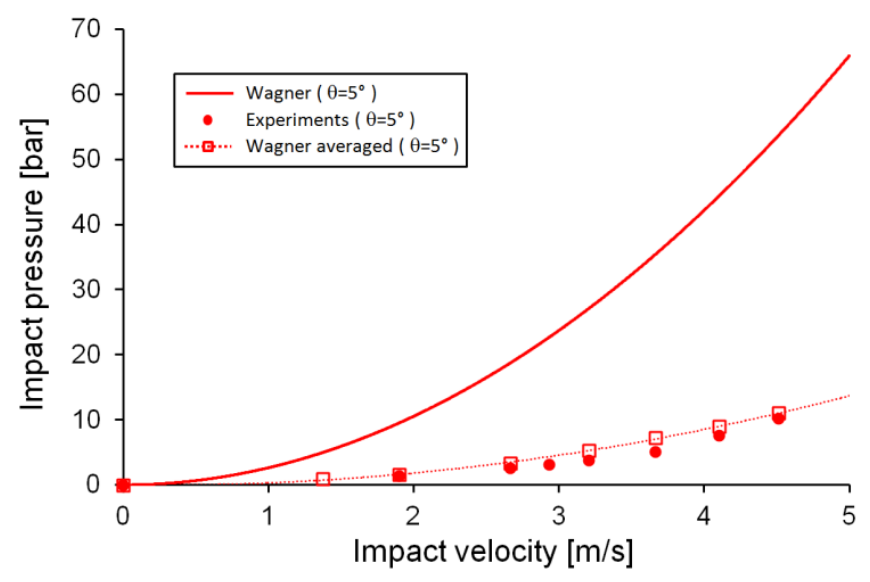

(b) 


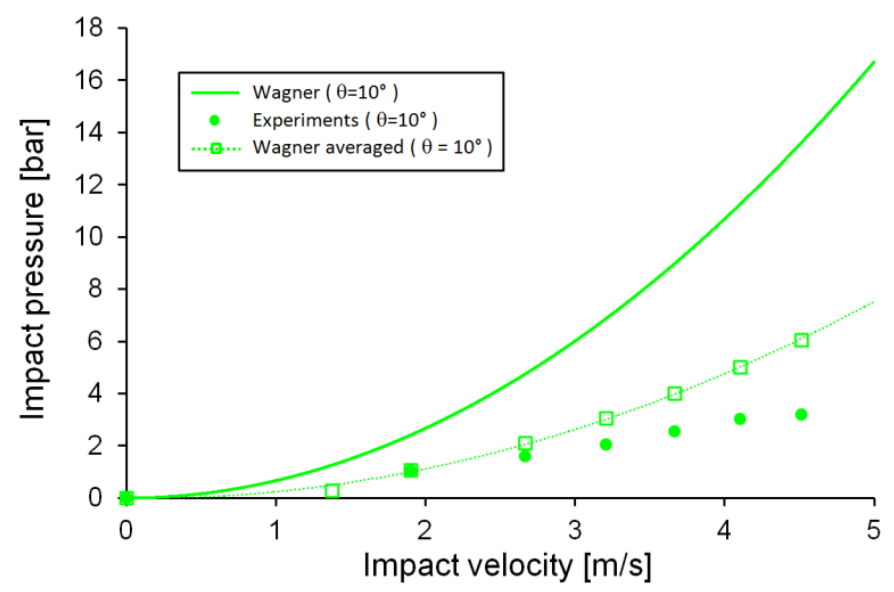

(c)

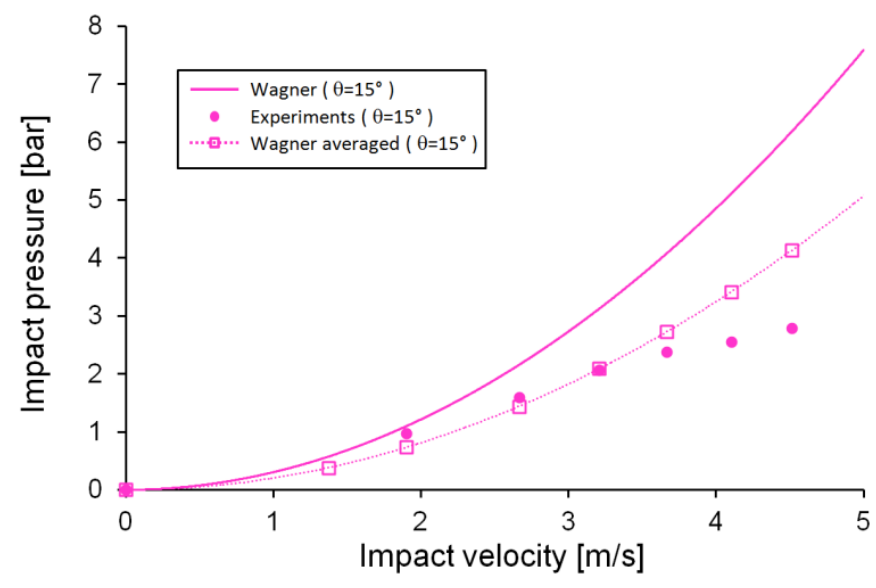

(d)

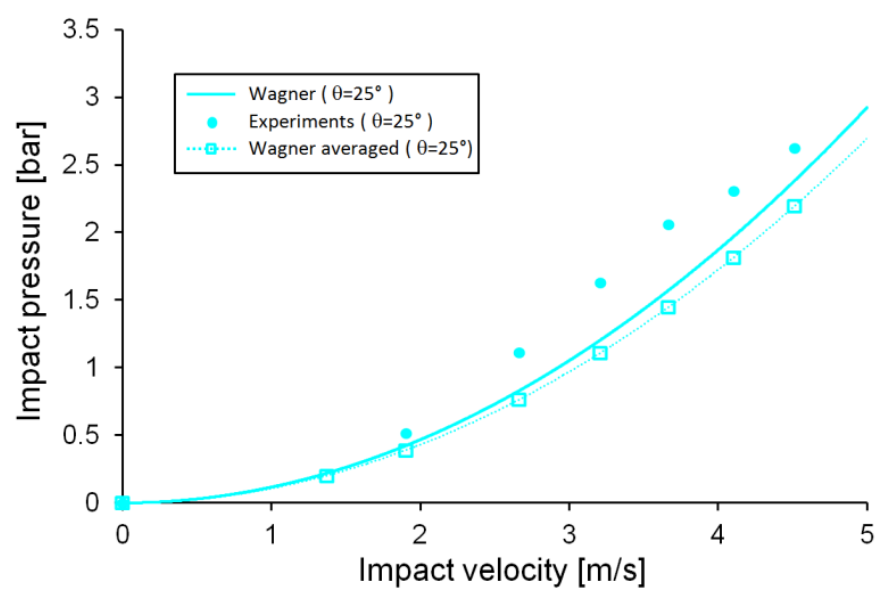

(e)

Figure 22: Comparison between the measured impact pressure values and the ones obtained from the corresponding theory, for deadrise angles (a) $0^{\circ}$, (b) $5^{\circ}$, (c) $10^{\circ}$, (d) $15^{\circ}$ and (e) $25^{\circ}$

Large differences can be found between the experimental and the corresponding theoretical values at $0^{\circ}, 5^{\circ}, 10^{\circ}$ and $15^{\circ}$. The theoretically predicted pressure peak values are in these cases much larger than the corresponding experimental ones. For the measurements at $25^{\circ}$, a much better agreement is found with the Wagner theory. Moreover, it is observed that in this case the experimental recordings are even slightly larger than the theoretical values. 
One explanation for the large differences found for most of the tested deadrise angles may be the fact that the pressure sensors measure over a certain diaphragm area. This means that the pressure measured at a certain point of the circumference of the cylinder is always an average of the pressures measured in the adjacent points which correspond to the sensor area. This is not the case in the Wagner theory where it is possible to determine the pressure exactly in one point at the circumference of the cylinder.

In the following paragraphs, the Wagner pressures will be averaged over the sensor area, to see the effect on the obtained pressure peak values. In order to do so, it is first required to express the pressure profile obtained at a certain moment of time as function of deadrise angle. Figure 24 illustrates as an example the pressure as function of deadrise angle at the moment that the maximum pressure is reached at $5^{\circ}$ deadrise angle for an impact velocity of $4.1 \mathrm{~m} / \mathrm{s}$. Averaging this 2D-Wagner pressure profile over the sensor area can be performed as following:

$$
p_{\text {wagner }, \text { avg }}=\frac{\int_{\theta}^{\theta+\Delta \theta} p_{\text {wagner }} d \theta}{\Delta \theta}
$$

With: $\Delta \theta=$ the angle corresponding with the sensor area.

Since the sensors used in this paper have a diaphragm of $d_{\text {sens }}=5 \mathrm{~mm}$ diameter, the angle can be calculated according to Figure 23 as:

$$
\Delta \theta=2 \arcsin \left(\frac{d_{\text {sens }} / 2}{R}\right)=1.82^{\circ}
$$

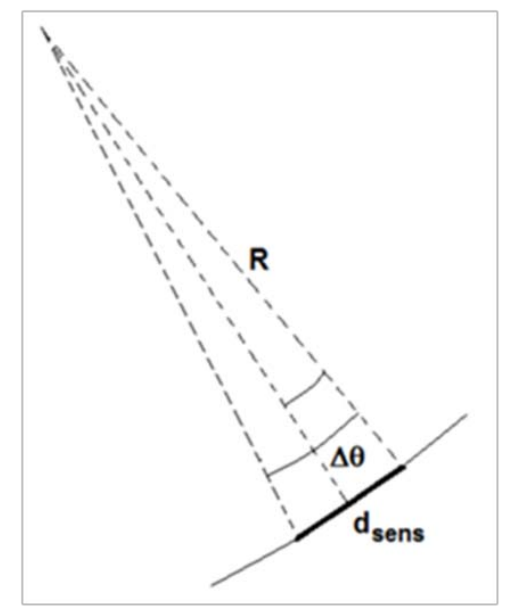

Figure 23: The angle $\Delta \theta$ corresponding with the pressure sensor diaphragm

The red curve in Figure 24 shows the averaging of the Wagner curve over this angle. It is found that this new pressure profile has a much smaller peak value which is closer to the experimental values. Figure 22 compares all the experimental impact pressures with the pressure peaks obtained from the averaged Wagner theory (except for the measurements at $0^{\circ}$ since the Wagner theory is not applicable there). It can be observed that for almost all measurements, the averaged Wagner theory approximates the measured values much better than the conventional Wagner theory. This is however not the case for the recordings performed at $25^{\circ}$ where a slightly larger difference is found. This may be related to the fact that flow separation starts to occur at $25^{\circ}$, which is not taken into consideration in the Wagner theory. Nevertheless, the agreement is still good. 


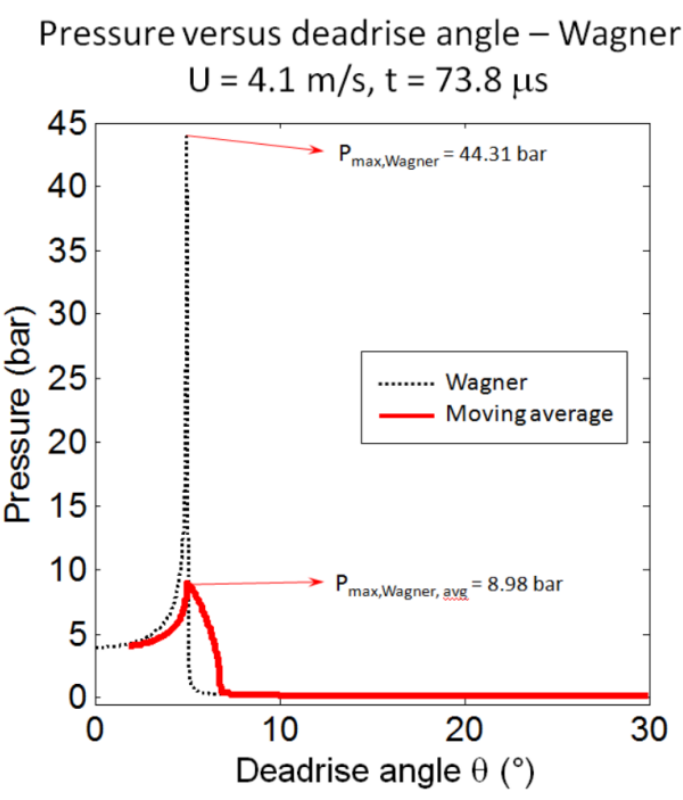

Figure 24: Wagner theory and its moving average as function of deadrise angle for an impact velocity of $4.1 \mathrm{~m} / \mathrm{s}$ at the moment that the peak value is reached at $5^{\circ}$ deadrise angle

But even after averaging, it is found that the theoretical impact pressures calculated by the averaged Wagner theory are a bit larger than the experimental values for deadrise angles $5^{\circ}, 10^{\circ}$ and $15^{\circ}$. This difference may be mainly explained by the fact that the cylinder in this paper is quasi-rigid, while in the Wagner theory a fully rigid cylinder is assumed. A small portion of the impact energy of the tested cylinder will be absorbed by small deformations resulting in smaller impact pressures. The difference may also be explained by the fact that in the theoretical approximation of Wagner, a constant entry velocity is assumed, while this is not the case in the experiments. In the experiments the body first accelerates under gravity and then decelerates due to the forces acting on it during water impact. However, it can be observed from Figure 10 that in the time span of the pressure pulses, the change in velocity is negligible which makes this effect rather limited.

\section{Conclusions}

This paper precisely investigates the local pressures which occur during cylindrical bottom slamming. The slamming event is hereby experimentally approximated by the vertical water entry problem of a horizontal quasirigid cylindrical model. A rigorously instrumented slamming set-up has been used to perform a large set of drop experiments on the model.

To link the recorded pressures to the cylinder's initial kinetic energy, the impact velocity has been measured. This makes the results independent of the experimental set-up which is used. It has been observed that theoretically estimated impact velocities are slightly larger than the experimentally recorded ones due to friction occurring between the impactor wheels and the vertical rails of the test set-up.

During the measurements, it has been observed that at the moment of first water contact, a high pressure pulse occurs at the bottom of the cylinder with a very short duration (in the order of a few hundred of microseconds). As the cylinder then penetrates the water, this pressure pulse travels along the cylindrical surface while the magnitude of the pulse decreases and the duration increases. The pressure pulse always occurs at the intersection of the cylindrical wall with the water surface, at the place where the water is compacted due to the impact. The pressure pulse disappears when the water starts to separate from the cylinder.

The measurements show that near the bottom of the cylinder where the first contact with the water occurs, the impact pressure increases very fast with increasing impact speed. The data points show a $4^{\text {th }}$ order relationship. This shows that for large impact speeds very large impact pressures will be encountered, which explains why in some cases damage may be introduced. For larger deadrise angles, no clear trends can be distinguished but the pressure magnitudes are much less critical. In these latter cases, the stochastic nature of the slamming event plays a role. 
When compared with theory, a good agreement can be observed between the measured impact pressures for deadrise angles larger than $4.25^{\circ}$ and the Wagner theory (Wagner, 1932), when the pressure pulses obtained by Wagner are averaged over the pressure sensor area. This shows that, if we could measure the pressure in one single point, the local loads due to water slamming are even higher than as recorded in the current experiments. Because the averaged Wagner theory is matching well with the sensor measurements, it may be stated that the conventional Wagner theory can be used for calculating impact pressures during design procedures. For deadrise angles smaller than $4.25^{\circ}$ angle, the Wagner theory is not valid anymore due to water compressibility playing its role during water impact. The von Kármán theory (von Kármán, 1929) which is then applicable shows large differences with the experiments. Since von Kármán only gives an expression for the maximum pressure values, it is not possible to average these results over the sensor area.

\section{Acknowledgments}

The authors would like to gratefully acknowledge the financing through a grant of the Fund for Scientific Research in Flanders (F.W.O.). They are very thankful to the Department of Coastal Engineering of Ghent University, especially to Prof. Dr. Ir. Julien De Rouck for the use of the experimental test set-up. They also like to thank Luc Vandenbroecke, Pascal Baele, Tom Versluys and Herman Van der Elst for their contribution to the practical work and the installation of the test set-up.

\section{References}

Campana, E., Carcaterra, A., Ciappi, E., Iafrati, A., 2000. Some insights into slamming forces: compressible and incompressible phases. Proceedings of the Institution of Mechanical Engineers, Part C: Journal of Mechanical Engineering Science 214 (6), 881-888.

Campbell, I., Weynberg, P., 1980. Measurement of parameters affecting slamming. Wolfson Unit for Marine Technology and Industrial Aerodynamics Univ. of Southampton. Report.

Colicchio, G., Greco, M., Miozzi, M., Lugni, C., 2009. Experimental and numerical investigation of the waterentry and water-exit of a circular cylinder, International Workshop on Water Waves and Floating Bodies. Zelegonorsk, Russia.

Faltinsen, O.M., 1990. Sea loads on ships and offshore structures.

Feit, D., Skalak, R., 1963. Impact on the surface of a compressible fluid. Columbia University New York. Greenhow, M., Lin, W.-M., 1983. Nonlinear-Free Surface Effects: Experiments and Theory. DTIC Document. HBM, 2013. Technical sheet and manual of the data acquisition system of type Gen5i.

Kistler, 2013. Technical sheet of accelerometer of type 8704B500.

Korobkin, A., 1994. Blunt-body impact on the free surface of a compressible liquid. Journal of Fluid Mechanics 263, 319-342.

Kübler, 2013. Technical sheet and installation guide of position encoder of type LIMES LI20/B1.

Lava, P., 2012. MatchID - Image Correlation \& Material Identification. Catholic University College Ghent, department of Mechanical Engineering, Gent.

Lin, M.-C., Shieh, L.-D., 1997. Flow visualization and pressure characteristics of a cylinder for water impact. Applied Ocean Research 19 (2), 101-112.

Palanivelu, S., De Pauw, S., Van Paepegem, W., Degrieck, J., Van Ackeren, J., Kakogiannis, D., Wastiels, J., Van Hemelrijck, D., Vantomme, J., 2009. Validation of digital image correlation technique for impact loading applications, Proceedings of ninth International conference on the mechanical and physical behaviour of materials under dynamic loading: Brussels, Belgium.

PCB Piezotronics, 2013a. General Piezoelectric theory and specific information on piezoelectric pressure sensors.

PCB Piezotronics, 2013b. Technical sheet of pressure transducer of type 102A06 and $102 B 06$.

Photron, 2013. Technical sheet and manual of the high speed camera of type APX-RS.

Van Nuffel, D., Vepa, K., De Baere, I., Degrieck, J., De Rouck, J., Van Paepegem, W., 2012. Study on the Parameters Influencing the Accuracy and Reproducibility of Dynamic Pressure Measurements at the Surface of a Rigid Body During Water Impact. Experimental Mechanics, 1-14.

Victor, S., 2007. Study of the slamming phenomena occurring on point absorbers: experiments and literature review, Department of Civil Engineering. Ghent University, Ghent.

von Kármán, T., 1929. The impact on seaplane floats during landing. National Advisory Committee for Aeronautics.

Wagner, H., 1932. Über Stoß-und Gleitvorgänge an der Oberfläche von Flüssigkeiten. ZAMM-Journal of Applied Mathematics and Mechanics/Zeitschrift für Angewandte Mathematik und Mechanik 12 (4), 193-215. 
Appendix A: Overview of the experimental and theoretical pressure peak values for different impact velocities and deadrise angles

\begin{tabular}{|c|c|c|c|c|c|c|c|c|c|c|c|c|c|c|c|c|c|}
\hline \multirow{19}{*}{ 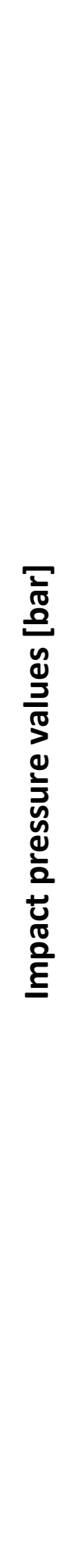 } & \multirow{4}{*}{$\stackrel{i n}{N}$} & 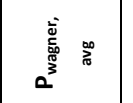 & 0 & & $\stackrel{N}{\sim}$ & & ֻ̊. & & $\begin{array}{l}\hat{\imath} \\
\vdots\end{array}$ & & $\underset{ت}{ت}$ & & $\stackrel{\text { nq }}{\text { - }}$ & & $\underset{-}{\vec{\infty}}$ & & $\stackrel{\overbrace{}}{i}$ \\
\hline & & 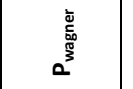 & 0 & $\stackrel{\text { Iิ }}{0}$ & 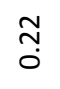 & $\stackrel{-1}{0}$ & ษั. & $\stackrel{n}{0}$ & $\begin{array}{l}\infty \\
\infty \\
0 \\
0\end{array}$ & ơ & $\underset{\sim}{\sim}$ & $\underset{\text { mे }}{\stackrel{\overbrace{}}{-}}$ & $\stackrel{n}{\text { n̊ }}$ & $\stackrel{\hat{~}}{i}$ & م્a & $\stackrel{\mathscr{C}}{\stackrel{\sim}{n}}$ & $\stackrel{\infty}{\sim}$ \\
\hline & & 0 & 0 & & & & $\stackrel{m}{0}$ & & $\stackrel{0}{\circ}$ & & $\begin{array}{l}\infty \\
0 \\
0\end{array}$ & & o̊ & & ơ & & न. \\
\hline & & $\stackrel{\frac{\infty}{0}}{D^{\infty}}$ & 0 & & & & กู่ & & $\underset{\sim}{\stackrel{7}{-}}$ & & $\begin{array}{l}n \\
\stackrel{0}{-} \\
-\end{array}$ & & 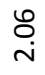 & & $\stackrel{\vec{m}}{i}$ & & $\underset{\sim}{\tilde{N}}$ \\
\hline & \multirow{4}{*}{ in } & 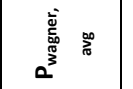 & 0 & & $\stackrel{\infty}{\dddot{\infty}}$ & & $\stackrel{m}{\stackrel{m}{0}}$ & & $\stackrel{\text { J }}{\text { S }}$ & & $\stackrel{\text { Oे }}{\text { in }}$ & & $\stackrel{m}{\stackrel{n}{i}}$ & & $\underset{\sim}{\vec{f}}$ & & $\stackrel{m}{\rightarrow}$ \\
\hline & & 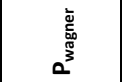 & 0 & $\stackrel{\vec{m}}{m}$ & in & $\begin{array}{l}-1 \\
0 \\
0\end{array}$ & $\stackrel{ت}{-}$ & $\underset{\sim}{\mathscr{r}}$ & 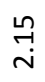 & $\underset{\sim}{\tilde{N}}$ & $\stackrel{m}{\rightarrow}$ & $\underset{\dot{m}}{\tilde{m}}$ & $\begin{array}{l}\infty \\
\stackrel{+}{+}\end{array}$ & 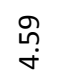 & $\begin{array}{l}\text { नै } \\
\text { in }\end{array}$ & i़ & $\begin{array}{l}\stackrel{0}{1} \\
\stackrel{-1}{6}\end{array}$ \\
\hline & & 0 & 0 & & & & $\stackrel{0}{0}$ & & & & $\stackrel{\infty}{-1}$ & & ָָ & & $\stackrel{\infty}{\rightarrow}$ & & $\underset{\sim}{\tilde{O}}$ \\
\hline & & 总 & 0 & & & & $\begin{array}{l}\text { ô } \\
\text { ô }\end{array}$ & & تُ & & $\underset{\text { i }}{\text { in }}$ & & 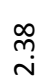 & & $\stackrel{\stackrel{\leftrightarrow}{\sim}}{\sim}$ & & $\stackrel{\infty}{\sim}$ \\
\hline & \multirow{4}{*}{ : } & 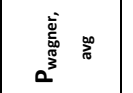 & 0 & & $\begin{array}{l}\mathscr{0} \\
\ddot{0}\end{array}$ & & $\underset{\sim}{\stackrel{\sim}{+}}$ & & in & & $\stackrel{o}{\dot{m}}$ & & $\stackrel{\leftrightarrow}{\dot{\tau}}$ & & 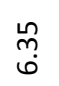 & & $\stackrel{\text { ô }}{\dot{0}}$ \\
\hline & & 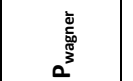 & 0 & $\stackrel{\infty}{0} \stackrel{0}{0}$ & $\underset{\sim}{\stackrel{\leftrightarrow}{\sim}}$ & $\stackrel{\infty}{\stackrel{\sim}{\sim}}$ & $\stackrel{\sim}{\stackrel{\sim}{\sim}}$ & 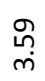 & $\underset{+}{\stackrel{+}{+}}$ & 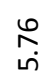 & 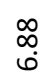 & 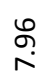 & 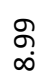 & - & $\stackrel{m}{\rightarrow}$ & $\underset{\exists}{\stackrel{\sim}{~}}$ & $\begin{array}{l}\stackrel{\varphi}{\dot{m}} \\
\ddot{\gamma}\end{array}$ \\
\hline & & 0 & 0 & & & & 웅 & & $\stackrel{m}{\overbrace{0}}$ & & ָָ & & $\stackrel{\sim}{\sim}$ & & $\underset{\text { ָ̃ }}{0}$ & & 궁 \\
\hline & & 㐘 & 0 & & & & $\stackrel{\text { Ln }}{\text { On }}$ & & $\begin{array}{l}\overrightarrow{6} \\
\stackrel{-}{-}\end{array}$ & & $\underset{\text { i }}{\text { D }}$ & & $\stackrel{\stackrel{\leftrightarrow}{N}}{\text { N }}$ & & $\stackrel{m}{\tilde{m}}$ & & $\stackrel{\sim}{m}$ \\
\hline & \multirow{4}{*}{ in } & 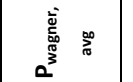 & 0 & & જુ & & $\underset{\text { - }}{\vec{G}}$ & & $\underset{\text { N̦ }}{\text { rat }}$ & & 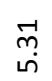 & & $\stackrel{\mathbb{N}}{N}$ & & $\begin{array}{l}\infty \\
\stackrel{\infty}{\infty}\end{array}$ & & $\exists$ \\
\hline & & 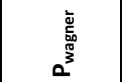 & 0 & $\begin{array}{l}\stackrel{0}{0} \\
\text { in }\end{array}$ & প్ & $\stackrel{\text { O্ }}{\Gamma}$ & 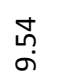 & $\underset{\sim}{\stackrel{\sim}{\sim}}$ & $\underset{\substack{\infty \\
\rightarrow \rightarrow}}{\wedge}$ & 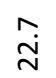 & $\stackrel{\sim}{\sim}$ & $\stackrel{+}{m}$ & $\stackrel{\text { ?n }}{\stackrel{m}{m}}$ & के & $\stackrel{n}{f}$ & 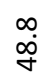 & 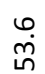 \\
\hline & & 0 & 0 & & & & ồ & & 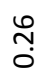 & $\begin{array}{c}\vec{m} \\
0 \\
0\end{array}$ & $\stackrel{m}{\text { f }}$ & & ָ̃ & & 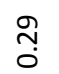 & & $\begin{array}{l}\stackrel{\infty}{\infty} \\
0 \\
0\end{array}$ \\
\hline & & : & 0 & & & & $\underset{+}{\vec{f}}$ & & 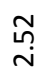 & $\begin{array}{l}\text { o. } \\
\text { r. }\end{array}$ & $\underset{m}{N}$ & & ஜٌ & & 资 & & ֻั \\
\hline & \multirow{3}{*}{ : } & 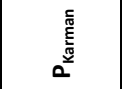 & 0 & تُ & 官 & $\stackrel{\stackrel{n}{\sim}}{\sim}$ & $\stackrel{\sim}{\infty}$ & 官 & के & \& & $\stackrel{\infty}{+}$ & ì & $\begin{array}{l}\text { જ̛ } \\
\text { में }\end{array}$ & $\stackrel{\sim}{\infty}$ & $\stackrel{n}{\rightarrow}$ & $\begin{array}{l}\stackrel{+}{0} \\
\dot{f}\end{array}$ & $\stackrel{n}{\leftrightarrow}$ \\
\hline & & 0 & 0 & $\stackrel{m}{0}$ & Iี & $\stackrel{\text { 궁 }}{\circ}$ & ने & ન્- & $\underset{\tilde{m}}{0}$ & $\stackrel{n}{\tilde{D}}$ & $\stackrel{̃}{0}$ & $\underset{m}{\tilde{o}}$ & $\begin{array}{c}m \\
m \\
0\end{array}$ & ? & $\underset{m}{\tilde{m}}$ & 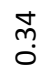 & $\stackrel{\infty}{\rightarrow}$ \\
\hline & & $\stackrel{\infty}{a^{0}}$ & 0 & भ̊̊ & $\dashv$ & $\underset{\sim}{\stackrel{\sim}{\sim}}$ & హ్ & $\stackrel{\bullet}{\dot{m}}$ & 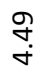 & 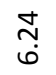 & ָ̆ & $\begin{array}{l}\stackrel{n}{\hat{\sigma}} \\
\stackrel{\sigma}{\sigma}\end{array}$ & $\stackrel{+}{\rightarrow}$ & $\stackrel{\nabla}{\ddot{r}}$ & 守 & $\begin{array}{l}\stackrel{\varphi}{\dot{\theta}} \\
\dot{-1}\end{array}$ & ભ̆ \\
\hline & 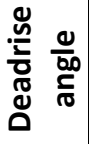 & 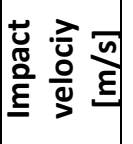 & 0 & & 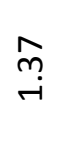 & $\begin{array}{l}\tilde{\varphi} \\
\stackrel{-}{-}\end{array}$ & $\stackrel{9}{\rightarrow}$ & $\stackrel{\sim}{\sim}$ & $\begin{array}{l}\mathscr{\ell} \\
\stackrel{0}{0}\end{array}$ & 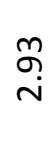 & $\stackrel{\vec{N}}{m}$ & $\stackrel{n}{\tilde{m}}$ & $\stackrel{\hat{n}}{m}$ & $\begin{array}{l}\text { ఏ } \\
\text { n் }\end{array}$ & $\stackrel{\vec{r}}{\dot{r}}$ & $\stackrel{m}{\sim}$ & मृ. \\
\hline
\end{tabular}

